\title{
NI AQUÍ NI ALLÁ: NOCIONES DE HOGAR Y SENTIDO DE PERTENENCIA EN EL CONTEXTO DE LA MIGRACIÓN
}

\section{Between Here and There: Notions of Home and Sense of Belonging in the Context of Migration}

Nem aqui nem lá: noções de lar e sentido de pertença no contexto da migração

Ricardo Gómez, Universidad de Washington (EE.uu.)

rgomez@uw.edu

Recibido: 15 de junio de 2016

Aceptado: 18 de abril de 2017

\section{RESUMEN}

La pregunta ¿dónde queda el hogar? es difícil, especialmente para los migrantes, quienes viven en un lugar diferente a su lugar de origen. Es particularmente difícil para aquellos que no tienen documentos y por lo tanto no tienen ni reconocimiento legal ni derechos, y están en constante riesgo de ser detenidos y deportados. A través de fotografía participativa y entrevistas, proceso que se ha llamado fotohistorias, se exploran experiencias humanas relacionadas con la migración en EE.uu., y en la frontera entre este y México. El artículo trata sobre las nociones contrapuestas relacionadas con el hogar y el sentido de pertenencia que surgieron en las experiencias compartidas por migrantes en estos dos contextos. Los migrantes evidenciaron diferentes nociones de "hogar" así como de "pertenencia", que reflejan los diferentes grados de transitoriedad e impermanencia en su cotidianidad.

Palabras clave migración, identidad, hogar, Estados Unidos, México. 


\section{DISERTACIONES}

AVANCES

\section{ABSTRACT}

The problem of identifying one's home is especially difficult for migrants, who live elsewhere than their place of origin. It is particularly difficult for those who don't have legal immigration status. Since they have no legal recognition or rights, they are in constant risk of being detained and deported. Using participatory photography and interviews, a process we call fotohistorias (photo histories), we explore the human experience related to migration in the United States and at the US-Mexico border. This paper discusses the notions of home and sense of belonging that emerge from experiences shared by migrants in these two different contexts. Different notions of "what is home" and "where do I belong" came to light, reflecting different degrees of transience and impermanence in daily life.

Keywords: Migration; identity; home; United States; Mexico.

\section{RESUMO}

A pergunta "onde fica o lar?" é difícil, especialmente para os migrantes, quem moram em um lugar diferente a seu lugar de origem. É particularmente difícil para aqueles que não têm documentos e portanto não tem reconhecimento legal nem direitos, e estão em constante risco de serem detidos e deportados. Através da fotografia participativa e entrevistas, processo que chamamos de Fotohistórias, exploramos experiências humanas relacionadas com a migração em EEUU, e na fronteira entre os Estados Unidos e o México. Este artigo trata sobre as noções contrapostas relacionadas com o lar e o sentido de pertença que surgiram nas experiências compartilhadas por migrantes nestes dois contextos diferentes. Os migrantes evidenciaram diferentes noções de "O que é lar?" assim como "Aonde pertenço?", evidenciando os diferentes graus de transitoriedade e impermanência em sua cotidianidade.

Palavras-chave migração, identidade, lar, Estados Unidos, México.

\section{Introducción}

¿Cuántas veces hemos escuchado que no hay lugar como el hogar? Hogar, dulce hogar. ¿Qué es el hogar?, ¿dónde queda?, ¿es donde naciste o donde creciste? La definición de hogar es particularmente compleja para un migrante para quien el sentido de esta palabra ha sido trasladado, pues el lugar de origen está necesariamente separado del lugar de estancia. ¿Es el hogar el lugar donde están sus ancestros, su familia y su comunidad?, ¿es el hogar el lugar donde actualmente está, a donde se está dirigiendo o al que está regresando? Además, la noción de hogar es especialmente compleja para los migrantes indocumentados, cuyo traslado o movimiento es enteramente incierto, impermanente y transitorio dado su estatus ilegal en el país. Hogar es lo que dejaron atrás, pero también lo que están creando en el nuevo lugar, a pesar de la ansiedad por la posibilidad de deportación. Este constante miedo a ser deportados agrega una dimensión única a la transitoriedad e impermanencia experimentadas por los migrantes indocumentados durante el proceso de construir un sentido de pertenencia en su nuevo hogar. 


\section{DISERTACIONES}

AVANCES

Estudios de audiencias y recepción: audiencias minoritarias y nuevas mediaciones

ISSN: 1856-9536

Doi: http://dx.doi.org/10.12804/revistas.urosario.edu.co/disertaciones/v11i1

Volumen 11, Número 1 / Enero-junio 2018

Versión PDF para imprimir desde

http://revistas.urosario.edu.co/index.php/disertaciones

Varios autores han estudiado las prácticas de información -búsqueda, uso y distribución (Savolainen 2008)— de comunidades migrantes, Caidi et al. (2010) ofrecen un buen resumen de muchos de ellos. Sin embargo, pocos han estudiado las prácticas de información de migrantes en quienes Nail (2015) califica como de extrema exclusión: los que buscan asilo, los trabajadores migrantes, los sans papier (sin papeles, en francés en el original) o indocumentados y los migrantes irregulares, entre otros. Todos ellos viven al margen de la vida política y extremadamente marginalizados y excluidos de la sociedad dominante. Las prácticas de información de estos grupos de migrantes han sido poco estudiados en la literatura de las ciencias de la información. Algunas excepciones que vale la pena resaltar incluyen estudios de servicios de bibliotecas para jornaleros (Jensen, 2002), análisis de los comportamientos de información de migrantes estacionales en trabajo agrícola (Fisher, Marcoux, Miller, Sanchez \& Ramirez Cunningham, 2004) y algunas publicaciones previas de nuestra investigación sobre jornaleros latinos en Washington (Baron, Neils \& Gomez, 2014; Newell, Gomez \& Guajardo, 2016; Vannini, Gomez \& Guajardo, 2016), entre otros.

De acuerdo con el Census Bureau de EE.uu., en el 2013 alrededor del 17\% de la población era de origen hispano o latino, que constituye la más grande minoría étnica y cultural de la nación. La mayoría de los cálculos indican que hay cerca de 11 millones de migrantes indocumentados en EE.Uu. La mayoría de ellos trabajan y pagan impuestos, tienen vidas productivas, crean familias, y sin embargo todos viven en una constante incertidumbre y con miedo de ser deportados. A través de nuestro trabajo con migrantes hispanos indocumentados en EE.uu., en la frontera EE.Uu.-México y en el sur de Colombia, descubrimos las diferentes facetas de hogar como el lugar donde está el corazón, donde viven las raíces y los sueños, donde existe un cordón umbilical que nos conecta con la vida. El hogar no es solo un lugar, es un sentimiento. La casa no es solo un lugar físico, es también uno que se imagina, un territorio (no solo geográfico sino también un lugar de identidad). El sentido de territorio puede permanecer incluso cuando el lugar geográfico cambia, pero los dos sentidos están dinámicamente conectados. El primero puede cambiar por desplazamientos, violencia, política y guerra, pero la identidad sigue conectada con el lugar que se deja atrás. Sin importar el espacio físico, nos esforzamos por hacer que un lugar se sienta como la casa, un lugar en el que construimos un sentido de pertenencia y donde establecemos una comunidad.

Este artículo explora las complejas nociones de hogar que son expresadas por los migrantes de dos escenarios diferentes: migrantes indocumentados en Seattle, Washington, EE.uu., y migrantes potenciales o recientemente deportados en Nogales, México (frontera EE.uu.-México). Usamos fotohistorias, un método de fotografía participativa y entrevistas, para estudiar las experiencias de vida de los migrantes y así entender la experiencia de migración desde su propia perspectiva, capturada en sus propias palabras e imágenes. En los contextos que estudiamos, la idea de hogar y el sentido de pertenencia surgieron como elementos centrales en la identidad y cultura de los participantes, cada uno con sus propias características. Para algunos, el hogar es de donde vienen, para otros, el hogar es a donde van y para otros el hogar es en donde están. Los significados de este concepto no son tan precisos, la riqueza y profundidad están en los detalles.

Primero presentamos el método de investigación (fotohistorias) y algunos detalles de cada contexto de investigación, continuamos con hallazgos que emergen en este estudio en relación con el sentido de pertenencia y la transitoriedad. Discutimos las implicaciones de lo que encontramos a la luz de prácticas recientes y estudios de migración. Aunque nuestro estudio se enfoca en migrantes hispanos en EE.uu., los aprendizajes pueden ser de interés 


\section{DISERTACIONES}

AVANCES

Estudios de audiencias y recepción: audiencias minoritarias y nuevas mediaciones

ISSN: 1856-9536

Doi: http://dx.doi.org/10.12804/revistas.urosario.edu.co/disertaciones/v11i1

Volumen 11, Número 1 / Enero-junio 2018

Versión PDF para imprimir desde

http://revistas.urosario.edu.co/index.php/disertaciones

para entender experiencias relacionadas con las nociones de hogar y sentido de pertenencia en las actuales olas de migrantes y refugiados en Europa.

\section{Métodos de investigación}

Las fotohistorias son un método que usa fotografía participativa y entrevistas para estudiar las experiencias de vida de migrantes, con el propósito de evidenciar la riqueza, diversidad y profundidad de sus raíces, experiencias y aspiraciones. El proceso de la fotografía participativa implica invitar a los participantes a tomar fotos, a que traigan sus propias fotos y a que tengan una entrevista abierta acerca de las mismas. Este método permite un entendimiento más profundo de la percepción y experiencias de los entrevistados en cuanto al tema de estudio.

La perspectiva de fotohistorias tiene cuatro fases principales (Gomez \& Vannini, 2015): 1. Colaboración con organizaciones locales; 2. Creación de fotos; 3. Conversación sobre las fotos, y 4. Análisis y difusión. Incluimos aquí ejemplos de las entrevistas para los diferentes temas que surgieron durante el análisis, revisados y editados para mayor claridad y brevedad. Los nombres fueron cambiados (y en el caso de la frontera EE.uu.-México se distorsionan las caras) para proteger la identidad de los participantes.

Las fotohistorias tienen una larga tradición de investigación participativa y visual, en particular en la fotografía participativa en ciencias sociales especialmente con migrantes (Frohmann, 2005; Holgate, Keles, \& Kumarappan, 2012; Kwok \& Ku, 2008; Rhodes et al., 2009; Sutherland \& Cheng, 2009). La fotografía participativa tiene por lo menos tres contribuciones importantes a nuestra investigación: 1. Empoderamiento: los participantes eligieron sobre qué querían hablar y fueron capaces de hacerlo y verse reflejados en sus propias experiencias. Reportaron frecuentemente sentirse empoderados, valorados y escuchados con un sentido de agencia mucho más fuerte. 2. Múltiples perspectivas: las fotos ayudan a cambiar las nociones preconcebidas de preguntas y respuestas tanto de los participantes como de los entrevistadores (Bignante, 2010). 3. Entendimiento más rico: hablar sobre las fotos (en lugar de, por ejemplo, sentimientos o miedo) permite que los participantes externalicen ideas y emociones complejas de forma más fácil.

\section{Dos contextos diferentes para entender las experiencias de hogar en relación a la migración}

Recogimos datos durante el 2014 y 2015 en dos lugares que representan diferentes momentos en la experiencia de migración: 1. En Nogales, México, en la frontera de EE.uu. y México, trabajando con la Kino Border Initiative, una organización local sin ánimo de lucro que dirige un asilo para migrantes que llegan de América Central y migrantes recientemente deportados, y 2. En Seattle, Washington, EE.uu., trabajando con Casa Latina, una organización local sin ánimo de lucro que dirige un centro de despacho de trabajo y otras oportunidades de educación para migrantes hispanos indocumentados. En cada lugar los participantes fueron voluntarios y recibieron compensación localmente apropiada, determinada en consulta con la organización con la que se estaba trabajando en cada caso.

La frontera de México y eE.uu. es la frontera terrestre con más actividad en el mundo y también la más vigilada por fuerzas de seguridad. De acuerdo con Pew (citado en Converti, 2015), durante los cinco meses entre octubre 


\section{DISERTACIONES}

AVANCES

Estudios de audiencias y recepción: audiencias minoritarias y nuevas mediaciones

ISSN: 1856-9536

Doi: http://dx.doi.org/10.12804/revistas.urosario.edu.co/disertaciones/v11i1

Volumen 11, Número 1 / Enero-junio 2018

Versión PDF para imprimir desde

http://revistas.urosario.edu.co/index.php/disertaciones

del 2013 y febrero del 2014 hubo más de 21000 migrantes que intentaron cruzar la frontera desde México. Por otro lado, en el 2013 hubo 438421 migrantes no-autorizados deportados desde EE.uu. (Gonzalez-Barrera \& Krogstad, 2014). Cruzar la frontera indocumentado no es fácil. Miles mueren en el intento cada año y miles más son detenidos. Nuestro sitio de estudio en Nogales, México, es parte del Sector de Tucson en la frontera de México y EE.Uu.: tuvo el mayor número de detenciones de migrantes indocumentados desde 1998 hasta 2013, así como el mayor número de muertes. Se estima que por lo menos 700 migrantes han muerto en ese sector entre 2010 y 2013 (Newell et al., 2016).

Por medio de la fotografía participativa y entrevistas con migrantes en Nogales, exploramos la impermanencia y transitoriedad de la experiencia de hogar vivida por migrantes indocumentados. Algunos habían sido recién deportados de eE.uu., mientras que otros recién habían llegado a Nogales desde el sur de México y otras capitales de América Central. Encontraron el refugio El Comedor de la Kino Border Iniciative, donde reciben comidas, suministros, ropa y servicios como atención médica, llamadas telefónicas y un lugar seguro para pasar el tiempo mientras deciden qué hacer después. En este punto de transición en la frontera, están lejos de su "hogar" y su lugar de pertenencia. Hechos tan simples como una llamada telefónica ponen a los migrantes en riesgo de extorsión y abuso (Newell \& Gomez, 2014), razón por la cual el trabajo de organizaciones humanitarias y de auxilio, como la Iniciativa Kino para la Frontera en Nogales, es aún más importante para proteger los derechos humanos básicos y la dignidad de los migrantes indocumentados.

Para explorar la experiencia de migración desde la perspectiva de migrantes hispanos indocumentados ya establecidos en EE.uU., usamos fotografía participativa y entrevistas a jornaleros y trabajadoras domésticas en Seattle, Washington. Aunque sus vidas todavía son inciertas y precarias, están un paso más allá de la transitoriedad e impermanencia de la vida en la frontera. Los migrantes en Seattle quieren contribuir a la sociedad en la que viven. En 2010 en el Estado de Washington, los migrantes indocumentados comprendieron aproximadamente el 3,4\% de la población estatal, y aproximadamente el 5,1\% de la fuerza de trabajo del Estado (Passel \& Cohn, 2011). Su trabajo no es insignificante, contribuye a la actividad económica con un estimado de $\$ 6,4$ billones de dólares del producto bruto del Estado (Perryman Group, 2008), y \$292,1 millones de dólares en impuestos locales del Estado (ITEP, 2013).

\section{La vida en la frontera: hogar es algún lugar entre aquí y allá}

La experiencia de la migración es una de traslado, una transición entre "aquí" y "allá". Esta experiencia de traslado es expresada con mayor crudeza en los participantes de fotohistorias que vivían temporalmente en la frontera de México y eE.uu.. Catracho y Chavaloson dos de los participantes que conocimos en el refugio en Nogales, México. Los dos están yendo hacia el norte, hacia EE.uu. Los dos expresan sentimientos de impermanencia cuando hablan de las fotos que tomaron la noche anterior a nuestro encuentro en el refugio donde pasaron la noche ${ }^{1}$.

1 Todas las entrevistas fueron transcritas, traducidas y editadas para mayor brevedad y claridad. 


\section{AVANCES}

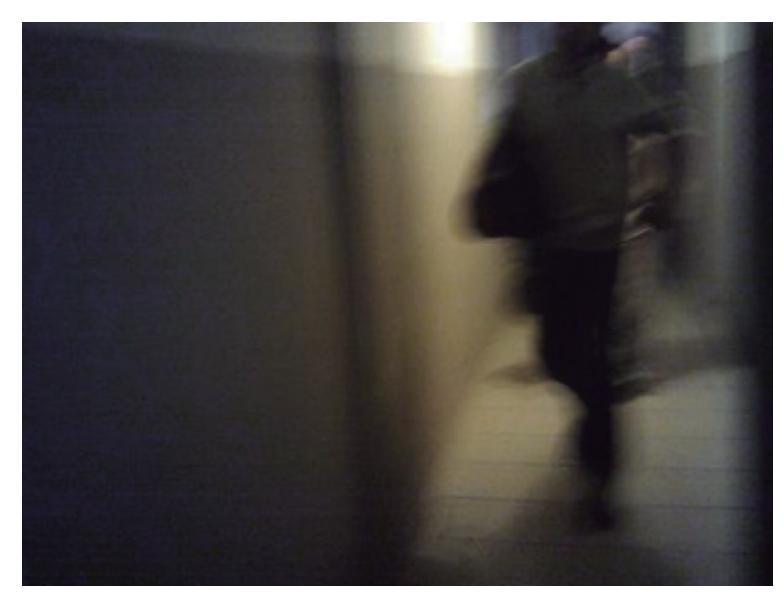

Pasillo del Albergue. Foto: Chavalo

Chavalo: Este es el pasillo del albergue. Está oscuro, como es el momento que estamos viviendo ahora. Es angosto y un poco oscuro, y está borroso, y no sabemos exactamente a dónde ir. Es un momento crítico en la vida que está borroso, como esta foto está borrosa.

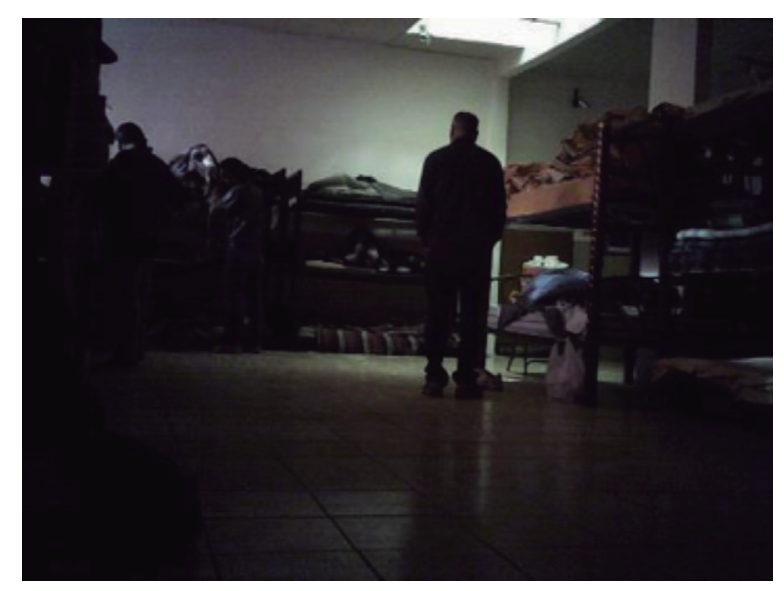

Albergue al amanecer. Foto: Catracho

Catracho: En esta foto ya es de día en el albergue, pero no han prendido la luz todavía así que no se puede ver nada. Todo eso son personas que durmieron allí, y es el comienzo de un nuevo día. Es una noche más en la frontera, pensando: ¿Vamos a seguir aquí?, ¿vamos a ir a otro punto para cruzar?, ¿qué es lo que vamos a hacer?

Nogales está justo en el medio del Desierto de Sonora que es soleado y caliente durante el día, pero que en las noches puede ser extremadamente frío. Además, es sobre todo inseguro para las migrantes pasar mucho tiempo en las calles, por las probabilidades de robo, extorsión, y el encuentro con traficantes de drogas y personas, por lo que pasan tanto tiempo como pueden en refugios que les proporcionan comida, calor y servicios humanitarios,

$$
174
$$




\section{DISERTACIONES}

AVANCES

mientras recuperan su salud y planean la siguiente movida. Chavalo escogió compartir una foto que podía ser fácilmente confundida con una foto tomada por accidente. Es oscura y borrosa, pero su interpretación es más poderosa y nítida que la imagen. Esta simboliza "el momento en que estamos ahora", con toda su incertidumbre. La foto de Catracho le da voz a las personas que aparecen en ella, oscuras e irreconocibles, en el amanecer de un nuevo día: "Qué vamos a hacer?"

Los migrantes en la frontera cargan todas sus pertenencias en una bolsa de plástico, o si tienen suerte, en un morral. Un migrante indocumentado con sus pertenencias en una bolsa de plástico es una expresión de "La nuda vida" descrita por el filósofo italiano Giorgio Agamben (1998) en Homo Sacer: aquél que puede ser matado y aún así no ser sacrificado. "La nuda vida" es la vida despojada de su ser político, ubicada afuera del orden político, sin acceso a las protecciones legales adquiridas por aquellos "dentro" del sistema (Agamben, 1998). Indocumentados, sin derechos, con una bolsa plástica como único contenedor de lo que resta de su humanidad, la falta de documentos en manos de los indocumentados es una expresión de falta de sus derechos humanos, de sus estatus como Homo Sacer: prescindible, aquél que puede ser asesinado y aún así no sacrificado.

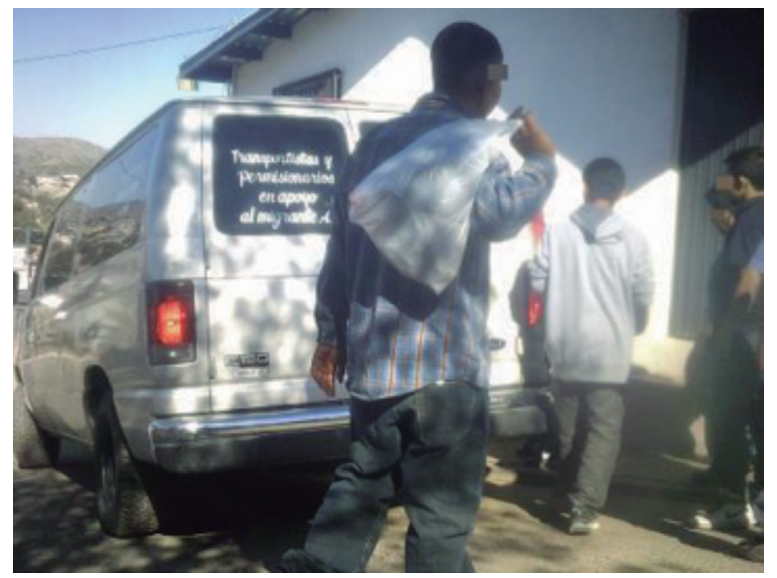

Migrante con bolsa plástica. Foto: Catracho

Catracho: Esta persona está cargando todas sus pertenencias en esa bolsa plástica. Se siente mal, porque es todo lo que tienes. Todo lo que tienes en este momento. ¡Claro que si la bolsa estuviera llena de dólares sería diferente!

Indocumentados, Desnudos. “iPero si estuviera llena de dólares sería diferente!”. Los migrantes en la frontera están fuera del Estado porque no tienen documentos ni dinero. Todo lo que tienen para ofrecer es su capacidad para trabajar, sus sueños de una vida mejor, la resiliencia y perseverancia para lograrlo todo.

La transitoriedad e impermanencia de la vida en la frontera está anclada en un solo objetivo: el muro. La frontera de México y ex.uu actualmente es un muro que corta la ciudad en dos, dejando a Nogales, México de un lado y Nogales, Arizona del otro. Llegar al muro es motivo de orgullo, un logro. Tocarlo un motivo de alegría. Chino, quien se recupera de una lesión en el pie que sufrió durante su viaje al norte desde su nativo Honduras, se refleja en su retrato, seguramente tomado por otro migrante que lo acompañó, parado junto al muro tocándolo por primera vez. 


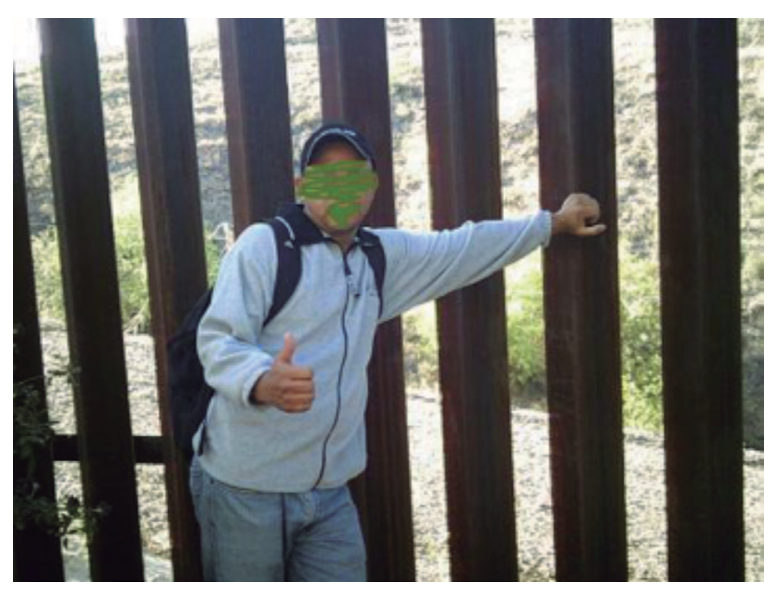

\section{Llegué al muro. Foto: Chino}

Chino: Aquí es cuando llegué al muro. Esta fue la primera vez que lo toqué. Me fui de mi casa con la idea de llegar a los Estados Unidos, y cuando llegué al muro solo lo quería cruzar o saltar por encima de una vez, y dejar de pensar que estaba todavía de este lado. Hay un carro de la migra allí como a unos cien metros y están mirando todo el tiempo. Me sentí bien de estar allí, hasta me dije que me iba a tomar una foto allí mismo junto al muro, con el desierto detrás.

Estoy durmiendo en un albergue que queda justo al lado del muro. Anoche estaba pensando que estaba durmiendo a solo dos minutos del muro, a dos minutos de estar al otro lado. De noche también podía ver que tienen luces por todas partes, y vi unos 4 o 5 carros de la migra para arriba y para abajo.

Esto es lo último que te está bloqueando, que te para de llegar donde tu familia y donde tus amigos. Yo quiero cruzar y llegar a mi meta, pero es muy difícil. Me sorprendió mucho que no puedo simplemente cruzar y caminar mis cinco días en el desierto hasta llegar al sitio donde alguien me pueda recoger o pueda tomar un bus. Yo creí que podría solo cruzar y comenzar a caminar en el desierto. Por eso es que tomé tantas fotos del muro.

Para los transmigrantes, el muro es el borde que separa el "aquí" y el "allá." Los sueños de Chino de una vida nueva y mejor empiezan justo al otro lado del muro, incluso con la presencia de carros policiales de la frontera y la anticipación de un recorrido de varios días a través del desierto. Ahora se para justo al lado del muro y lo toca. De hecho duerme a pocos metros de él: desde algunas de las ventanas del refugio se lo alcanza a ver, y lo que se ve al otro lado es Estados Unidos.

Los migrantes en la frontera muestran una aguda conciencia de estar en un punto pivotante, el punto de transición entre el "aquí" y el "allá". Un punto desde donde el regreso es percibido como derrota. "Yo estoy acá", dice Chino, parado bajo una señalización en la autopista que indica la dirección de la frontera con EE.uu. Pero para él, la señalización no está apuntando hacia el frente, está hacia abajo, señalándolo a él, mostrando su momento presente en la frontera. 

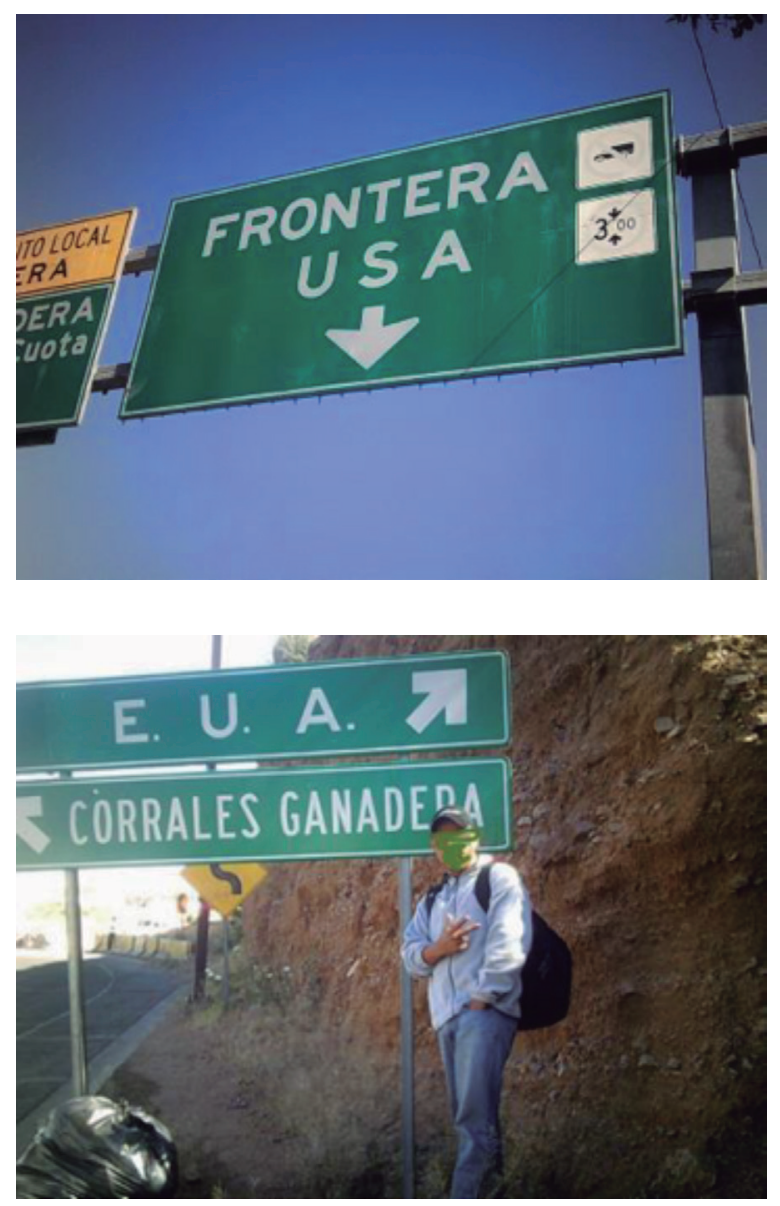

Estoy en la frontera. Fotos: Chino

Chino: Este letrero está allí para recordarme de cuando estaba aquí. Dice: "Frontera usA". La frontera de los EE.uU está aquí mismo. Me pareció interesante que yo estoy aquí, la frontera está aquí, y hay una flecha que apunta aquí mismo hacia abajo, hacia donde estoy: aquí es donde estoy ahora. Y ese soy yo parado al lado de la flecha diciendo: "Para los Estados, por aquí".

Para los migrantes en la frontera, participar en las fotohistorias fue como un juego, una forma de entretenimiento, una manera de pasar el tiempo y documentar su (transitoria) vida en el pueblo de la frontera, justo antes de embarcarse (o reembarcarse) en sus viajes como migrantes indocumentados. Como un turista en un lugar emblemático, Chino le manda postales a sus amigos y a su familia, Chino captura el tiempo de su estadía en la frontera. "Ese soy yo parado al lado de la flecha."

En el clímax de la impermanencia, durmiendo justo al lado de la frontera, buscando la manera de cruzar, los migrantes se regocijan al encontrar un refugio para recuperar un poco de humanidad perdida en "la vida nuda" del Homo Sacer corporizado en los migrantes indocumentados. Chiapas mira la foto que tomó dentro del refugio que muestra el momento en que se están yendo a dormir y refleja la transitoriedad de su amistad. 


\section{DISERTACIONES}

AVANCES

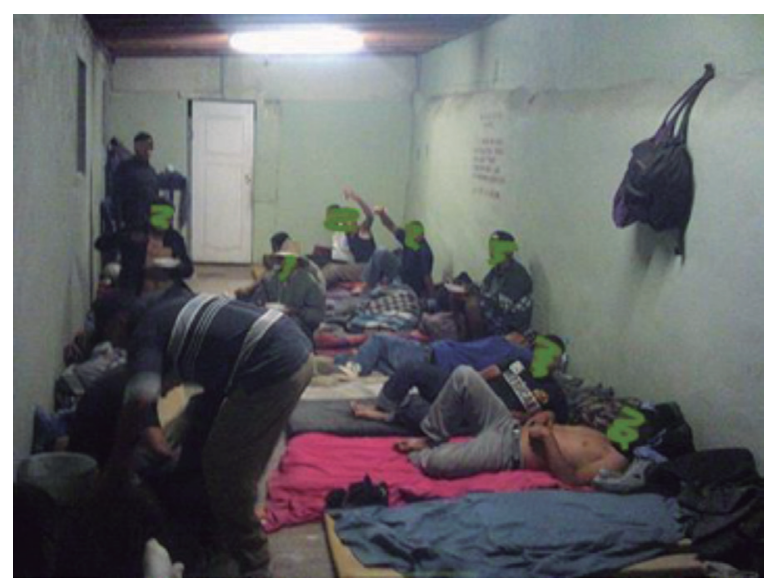

A dormir en el albergue. Foto: Chiapas

Chiapas: Si yo veo esta foto otra vez en unos 5 años podría decir: “¿Dónde está esta persona?, ¿logró llegar a los Estados o estará de vuelta en su país? Estamos juntos aquí hoy, pero tan pronto como nos apartemos, cada uno en sus diferentes caminos, ya no nos volveremos a ver. Tal vez logremos cruzar, pero nunca estaremos juntos otra vez. Por eso tomé esta foto con todos, aquí estamos todos juntos como estamos aquí hoy.

Ya está sufriendo la pérdida de los amigos que acaba de hacer, todos juntos en la impermanencia de su momento de transición, de sus vidas en la frontera. Chavalo también habla de su foto de los migrantes durmiendo en el piso del refugio, su hogar temporal.

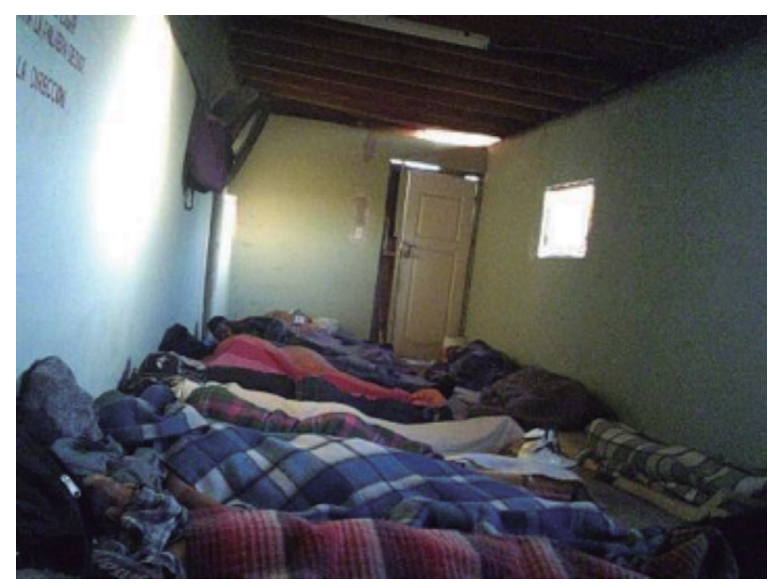

Amanecer en el albergue. Foto: Chavalo

Chavalo: Este es el albergue donde dormí. Esta es mi casa hoy. Allí puedo pasar la noche y estar seguro. Estamos en un lugar seguro, no estamos durmiendo en la calle o solos junto a los rieles del tren. Es muy difícil estar solo y en la calle. Aquí por lo menos estamos con otros y estamos seguros. 


\section{DISERTACIONES}

AVANCES

Una colchoneta en el piso y una cobija, un cuarto pequeño lleno de docenas de migrantes durmiendo; esto es mejor que dormir afuera en la calle o al lado de las vías del ferrocarril donde no se tiene nada, no se es nadie. Aquí, por lo menos, no están solos, están seguros. Están a punto de cruzar la frontera hacia la "vida nuda" de migrantes indocumentados en Estados Unidos. La vida como migrante indocumentado no es fácil y pronto lo van a aprender. No tienen documentos y por lo tanto no tienen derechos. Seguro hay trabajos para hacer, pero las condiciones son precarias, les pagan poco y los sueños de un regreso triunfante pronto se empiezan a desvanecer. A medida que construyen su vida en el nuevo lugar, las memorias del hogar que dejaron atrás empiezan a perseguirlos y se pueden exacerbar por el constante miedo a la detención y deportación. Pero los desafíos son muy grandes como para considerar regresar. Ellos necesitan seguir moviéndose y la única dirección es hacia adelante.

\section{La vida en el norte: el hogar es aquí pero también allá}

El segundo lugar de nuestra investigación fue en un centro de despacho de trabajos en Seattle, Washington, EE.uv: Casa Latina. Este centro fue fundado hace 25 años por una comunidad de activistas con la misión de empoderar a los migrantes latinos a través de oportunidades educativas y económicas. Estudios pasados muestran cómo los trabajadores valoran la oportunidad de obtener sus trabajos a través del servicio de despacho ofrecido por Casa Latina, pero más importante que eso, valoran el sentido de comunidad, la dignidad y el respeto que reciben allá (Baron et al., 2014). Por medio de oportunidades educativas y económicas inspiradas en educación popular y desarrollo participativo, Casa Latina ayuda a humanizar y redignificar la experiencia de la "nuda vida" de los migrantes indocumentados en Seattle.

La experiencia de migración de los participantes en Seattle incluyó, en algún momento, un cruce de frontera exitoso. Para algunos, el cruce de la frontera era antes algo cotidiano, un viaje normal para ir al trabajo. Por ejemplo, Infante recuerda:

Por esos días en Los Ángeles muchos de nosotros cruzábamos por diferentes fronteras, por Tijuana, Mexi-

cali, Algodones o Tecate, casi todas están conectadas a Los Ángeles. Yo he cruzado por todas esas fronte-

ras. Donde más me gustó fue en Mexicali, porque cada día yo trabajaba de este lado cosechando melones,

y a medio día te pagan. En ese tiempo la frontera era apenas un hilo, algunos alambres, eso era todo. No

había nada. En ese tiempo se cruzaba más fácilmente.

Juan, por su parte, ni siquiera sabía a dónde estaba yendo cuando cruzó la frontera por primera vez, cuando era un adolescente que venía de Guatemala. Desde ese momento ha ido y venido muchas veces, y recientemente fue secuestrado por traficantes de drogas y forzado a llevar una carga grande de drogas a través de la frontera, situación que lo hizo calificar como un caso especial de inmigración por ser víctima de un crimen. Esta preferencia especial es algo usualmente reservado para mujeres quienes han sido violadas por los contrabandistas, una situación muy común. Así describe Juan la primera vez que cruzó la frontera y entró a EE.uu., mientras nos mostraba una foto que le tomó al mapa de Texas. 


\section{DISERTACIONES}

AVANCES

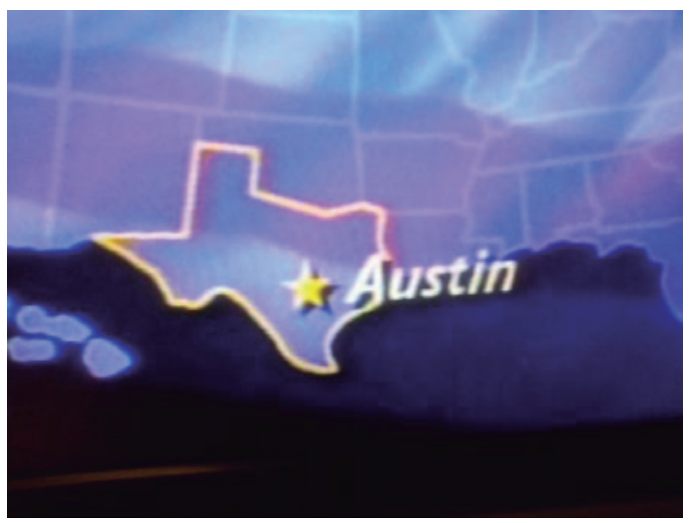

Entré por Texas. Foto: Juan

Juan: Bueno, en esta foto se ve Texas. Este fue el primer estado en el que entré a los Estados Unidos. Fue el 9 de agosto de 1988, a las 9 a.m. Eso es hace como 25 años. Yo no sabía qué era lo que iba a pasar. Yo vi gente cruzando y me fui caminando detrás de ellos. No sabía a dónde iba. Vi personas caminando y escondiéndose y yo los seguí. Y cuando menos pensé, estaba en los Estados.

Como Juan, la mayoría de trabajadores en Casa Latina han vivido en muchos lugares antes de llegar a Seattle. Todos encontraron la forma de llegar allá para empezar de nuevo. Seattle tiene inviernos suaves, policías liberales y salarios más altos que otros Estados. Juan describe cómo llegó a Seattle y cómo regresó, hablando sobre la foto que tomó de la King Street Station al atardecer.

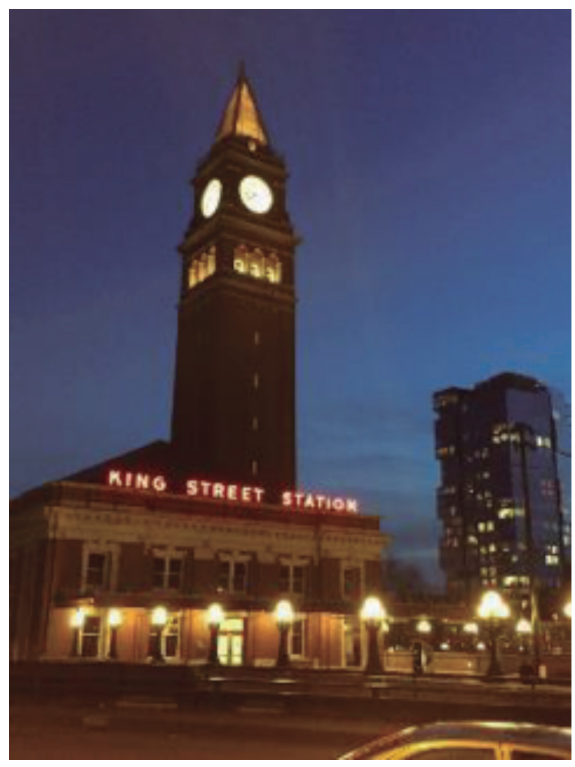

Seattle es una gran ciudad. Foto: Juan 
Juan: Seattle es una gran ciudad. Hay mucho dinero aquí, y es donde te pagan mejor. Yo he trabajado en Phoenix y en California, donde te pagan $\$ 5$ o $\$ 6$ us por hora, dependiendo del patrón y del trabajo. Pero aquí en Seattle, haciendo trabajo de jardinería, puedo ganar $\$ 18$ o \$20 us por hora. El único problema es que no tengo muchos patrones ahora, porque como me fui y después regresé estoy comenzando de nuevo aquí en Seattle.

La mayoría de los migrantes llegaron buscando un trabajo y soñaban con regresar a su casa después de pocos años, con dinero ahorrado. Algunos se sorprenden al darse cuenta de que, de repente, varios años han pasado desde que llegaron por primera vez pensando "esto es temporal". Con nuestra cámara en sus manos Gilda se fue a caminar un rato largo cerca al lago Washington. Tomó fotos de árboles, de la naturaleza, de las personas caminando por el parque, de personas sentadas mirando el agua.

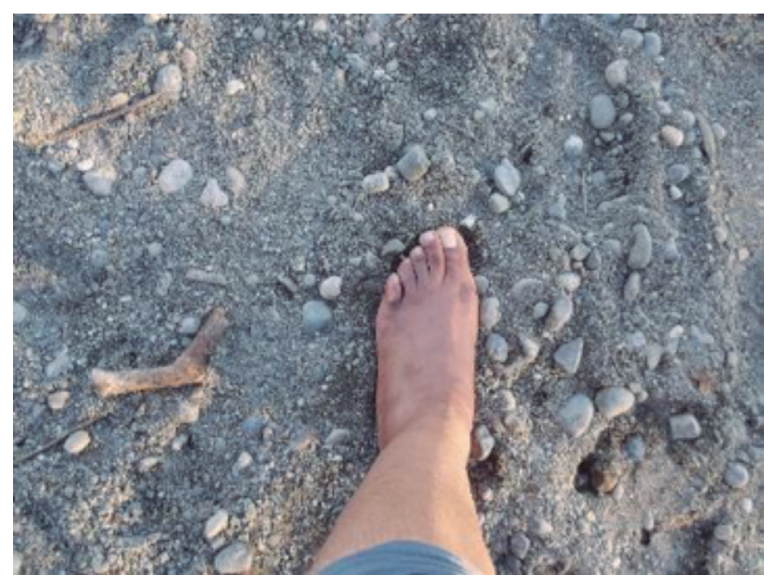

\section{Cuando camino en la arena siento libertad. Foto: Gilda}

Gilda: Yo quería oler la arena y la playa. Quería conectarme con el olor del agua, así que me quité los zapatos y las medias porque quería poner mis pies en la arena y conectar con la arena. Yo hacía esto en mi pueblo. Sentía que estaba recibiendo toda la energía de la arena. Por un momento me sentí libre. Es como si hubiera regresado al pasado, a como era yo antes de venir a los Estados Unidos. Cuando me quito los zapatos y camino en la arena siento libertad.

Así es como una foto de un pie descalzo en la arena significa libertad. “¿Dónde están tus raíces?”, le preguntamos a Gilda después de que habló sobre las raíces de un árbol del parque. Después de una pausa respondió: 


\section{DISERTACIONES}

AVANCES

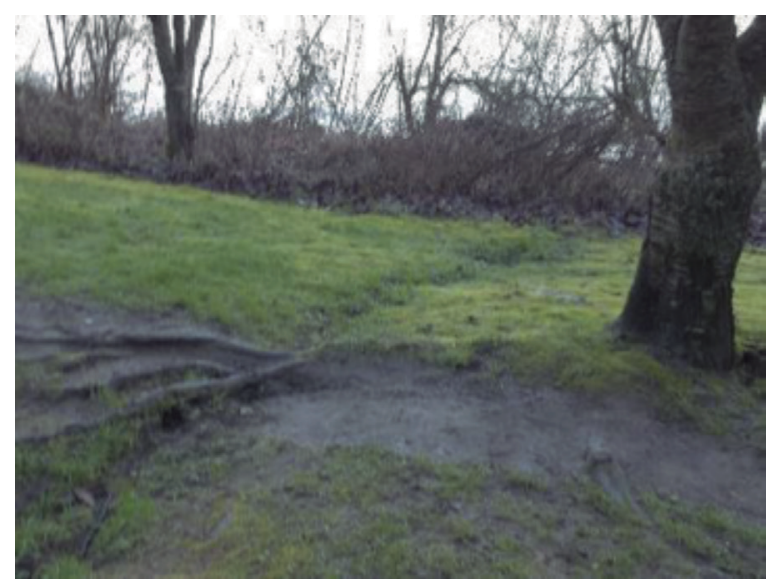

Raíces. Foto: Gilda

-Gilda: Lo que me atrajo a esta foto es que alguien puede ver esta imagen y no ve nada. Para mi tiene un sentido muy importante porque el árbol está tratando de sumergir sus raíces. Desde aquí no se ve cómo las raíces están todas interrelacionadas hasta que salen a la superficie. Cuando yo vi el árbol y sus raíces me dije: "Wow, me identifico con ese árbol porque siento que también puedo tener raíces que crecen y puedo mantener esas raíces muy sólidas".

-Sara: ¿Dónde están tus raíces?

-Gilda: Wow. Esa es una pregunta muy fuerte. Mis raíces... Yo llevo mis raíces conmigo. ¿Entiendes? Siempre estoy pensando en mis abuelos y mis padres. Mis padres me trajeron a este mundo. También, mis padres me criaron y me enseñaron muchas cosas. Además, yo pienso en mis abuelos y antepasados. Esta es una raíz. Debido a toda la lucha que tuvieron, es la razón por la que yo puedo estar aquí. Esto me ayuda a seguir adelante y continuar trabajando. Dondequiera que voy, siento que mis raíces están conmigo. Yo las llevo conmigo.

Gilda está haciendo un hogar en Seattle, con un trabajo que ama, en el cual puede estar al servicio de otros y con un lugar propio.

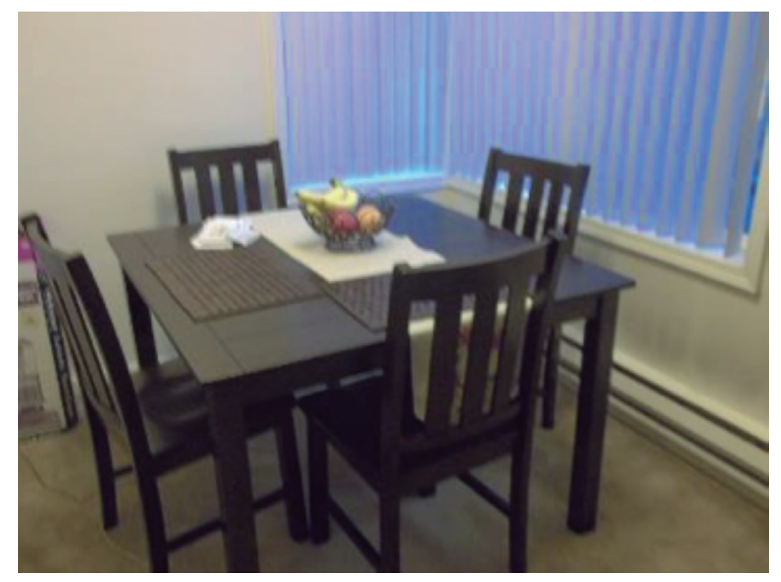

Éste es mi hogar. Foto: Gilda 


\section{DISERTACIONES}

AVANCES

Gilda: Éste es mi hogar. Hay una mesa con cuatro asientos. ¡Si solo pudiera decirte cuántas cosas han sucedido en esta mesa! Comemos, junto con mi hermana y sus hijos y su esposo. También me siento allí con mi novio y con amigos que vienen a visitarme. Para mí este lugar es muy sagrado. Es mi lugar favorito en el mundo. Mi propio espacio. Aquí tengo la sensación de que yo soy.

Gilda nos contó, con lágrimas en los ojos, la emoción que sintió cuando le dieron la llave del apartamento que ella había arrendado. No podía creerlo. Un lugar propio, algo a lo que se le puede llamar hogar.

Y aun así añora "el otro lado", el lugar donde su ombligo está enterrado. Además de Gilda, otros migrantes también compartieron fotos de sus apartamentos. Salomón y Carlos, por ejemplo, compartieron fotos de sus hogares, aunque expresaron cosas diferentes en cuanto al sentido de pertenencia.

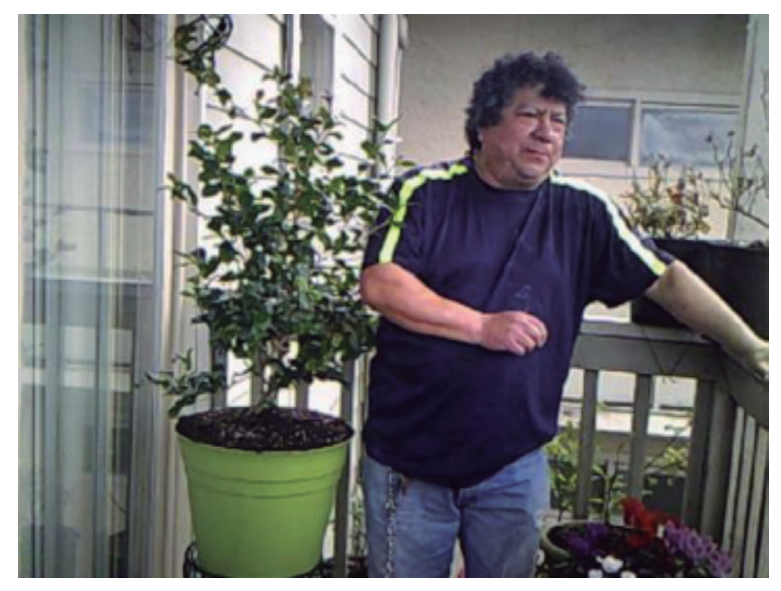

Una planta en mi balcón. Foto: Carlos

-Carlos: Este es el patio de mi casa. Ese soy yo. Esa es una plantita que tengo para decoración en mi patio. Me gusta verme allí en mi patio. No me siento orgulloso ni avergonzado ni nada.

-Ricardo: ¿Considera que Seattle es su casa?

-Carlos: Sí. Yo sé que vengo de El Salvador, pero esta es mi casa. He estado aquí ya por muchos años. 


\section{DISERTACIONES}

\section{AVANCES}

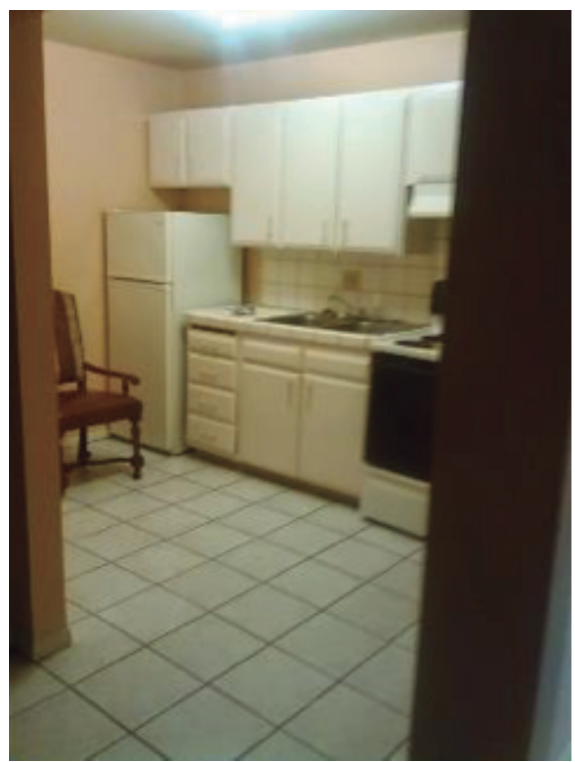

Mi apartamento Foto: Salomón

-Salomón: Esto es cuando primero llegué a Seattle. Este es el apartamento que renté. Esta es mi cocina.

-Ricardo: $Y$ en el futuro, ¿quiere seguir viviendo aquí?

-Salomón: Oh no, para el futuro, todo es transformación y cambio. Seattle es una linda ciudad, pero hay ciudades mejores. Quiero ver el mundo, quiero seguir viajando.

Carlos ha hecho que Seattle sea su hogar, vive en un apartamento, habla suficiente inglés y ha aprendido suficientes habilidades para tener diferentes trabajos todo el tiempo. Él se imagina siendo viejo en Seattle, pero si eso no funciona, preferiría devolverse a Guatemala que al Salvador que es su lugar de origen. Dice que le gusta más allá. Carlos no extraña el lugar donde está su ombligo; su hogar es donde él está ahora.

Salomón, por su parte, expresó un sentido de aventura y viaje parecido al de Chopin en la frontera y no siente que tenga raíces que lo aten a alguna parte. Cree en el autodesarrollo y en el crecimiento personal y busca constantemente oportunidades para aprender y estar al servicio de los otros. 


\section{DISERTACIONES}

\section{AVANCES}

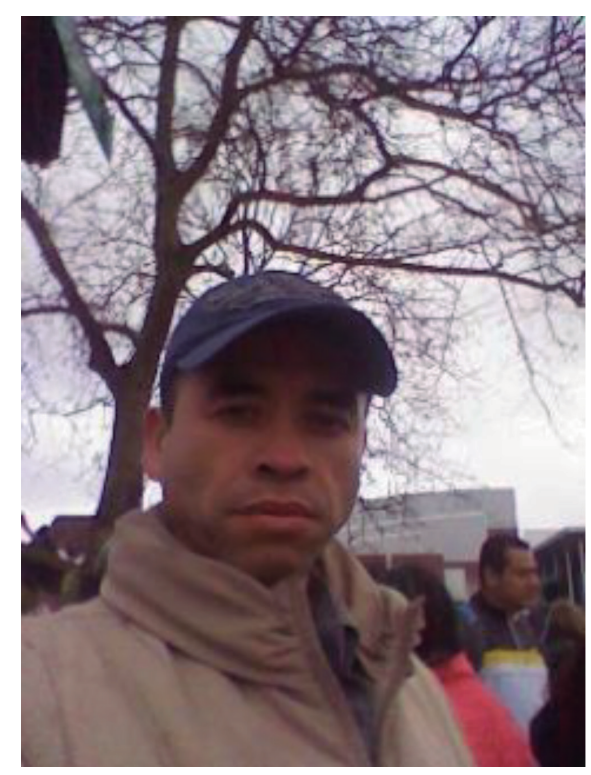

Autoretrato. Foto: Salomón

Salomón: El trabajo que yo hago contribuye a la vida de otros. Yo quiero que otros vean que no nos estamos escondiendo, que podemos mostrarnos. Que luchamos y decimos: "Sí se puede" y que nos preparamos y trabajamos para tomar diferentes acciones, porque solo tener un empleo, o dos o tres empleos, no es suficiente. También hay que desarrollarse como persona.

Salomón siente que su apartamento en Seattle es una casa temporal y está abierto a la aventura de aprender nuevas cosas, conocer otros sitios, no quedarse en un único lugar. Su sentido de aventura y no-raíces lo expresó también Ventura, uno de los participantes más viejos en nuestra investigación en Seattle. Por muchos años Ventura fue de un lugar a otro, montándose a un tren para ir a otra ciudad cuando sentía que necesitaba un cambio. El habla sobre sus viajes y aventuras con un brillo en sus ojos, con la sonrisa de una persona que cuenta cuentos entretenidos. 


\section{DISERTACIONES}

AVANCES

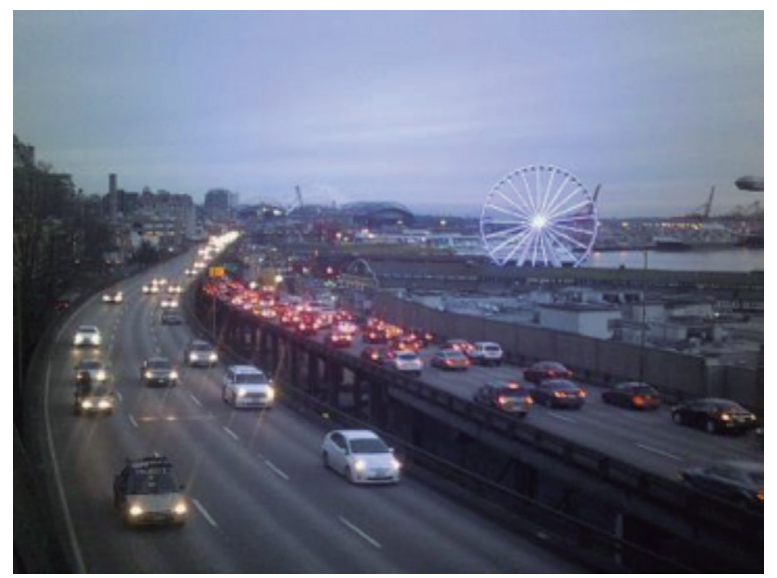

Tal vez voy a morir aquí. Foto: Ventura

Ventura: La primera vez que entré a EE.uU. tenía 16 años. Ahora tengo 56. Soy de Guatemala. Pasé por México, por todo el país, en trenes de carga, en "la Bestia". En ese entonces no había así tanta gente. Pasé por todos los Estados, pero no me gustaron. Saltaba en los vagones y sin dinero, así es como viajaba todo el tiempo. Trenes, vagones, escondiéndome entre el carbón, en los tanques, los que llevan propano, los que llevan leña, me escondía allí. Me metía por encima, ni sabiendo a dónde es que iba el tren. Y dondequiera que el tren se paraba, miraba alrededor y encontraba un camino. Y este fue mi mundo por muchos años. Yo he cruzado la frontera muchas veces. Ese era mi mundo, siempre en movimiento. Yo me hice viejo en ese mundo. Si no hubiera conocido Seattle de pronto estaría todavía allá, yendo para arriba y para abajo en los trenes. No quiero ir a Guatemala. Yo quiero estar aquí. Tal vez voy a morir aquí, o tal vez muera en otra parte.

Ventura, como Carlos, está contento con el nuevo hogar que ha construido en Seattle y no quiere volver a su país de origen. "De pronto cuando esté muerto", dice Ventura con una sonrisa. Carlos y Ventura han crecido sus raíces lejos de su lugar de origen, así uno viva en un apartamento, con un patio y una planta, y el otro no tenga casa y viva en la calle.

La experiencia de hogar tiene una expresión muy concreta para los migrantes indocumentados que no tienen casa, que están en la calle. 


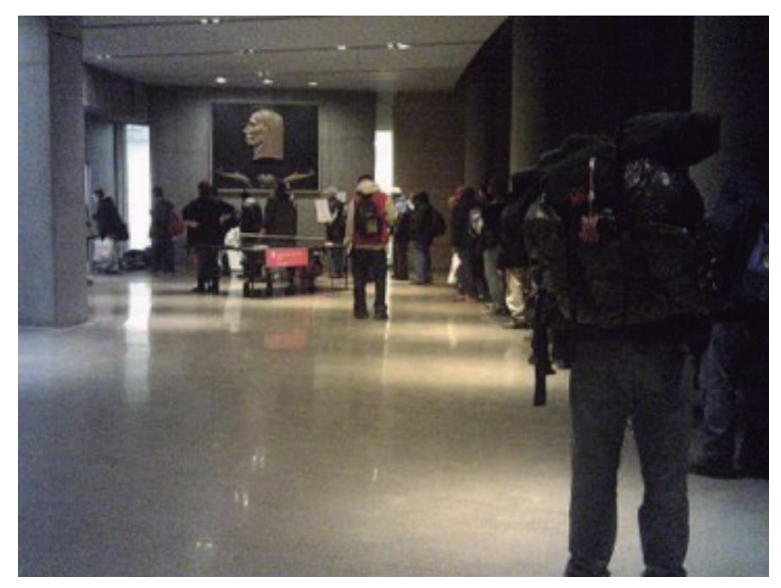

Durmiendo en la alcaldía. Foto: Ventura

Ventura: Yo vivo en un albergue en la alcaldía, con otras personas que tampoco tienen dónde dormir. Desde que llegué a Seattle me he quedado allí, sobre un colchón. Mi casa, mi hogar, es donde caiga. Como dice el dicho, donde cae la noche, también cae el cuerpo.

La extrema transitoriedad de los migrantes indocumentados sin casa en Seattle evoca la experiencia de los migrantes que están en los refugios en Nogales en la frontera. Pero el no tener casa no es un estado permanente: las personas tienen y no tienen casa (Lee, Tyler \& Wright, 2010). Carlos, quien ahora tiene un apartamento y considera que Seattle es su hogar, antes vivía en la calle. Infante también ha vivido en la calle, y lo recuerda al compartir con nosotros una foto de uno de sus amigos.

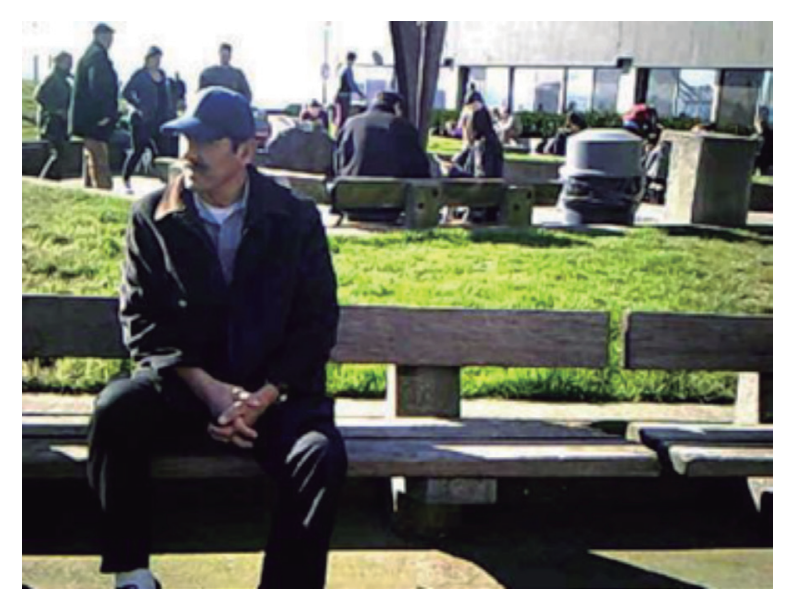

Mi amigo sin hogar. Foto: Infante

Infante: Tomé esta foto porque él es un tipo muy divertido. Él también trabaja aquí en Casa Latina. Yo viví en las calles por muchos años, y conozco a casi todo el mundo en las calles. Por muchos años yo dormía donde podía, 


\section{DISERTACIONES}

AVANCES

y nunca me importaba. Yo solo vivo un día a la vez. Ahora tengo un pequeño apartamento, porque tengo un amigo que me ha ayudado mucho. Si no, todavía estaría viviendo afuera en las calles.

Otros trabajadores en Casa Latina también están en la calle o lo han estado en algún momento. Con un gesto desgarrador uno de los participantes nos contó que había entregado su copia del libro con todas las fotos y las historias que había recogido en este proyecto porque no tenía hogar. "No tengo ningún lugar para guardarlo así que se lo di a alguien más", dijo cuando le preguntamos qué había pasado con este. Vivir en la calle es parte de la realidad cuando se es un migrante indocumentado que trabaja día a día.

En 1950 Hannah Arendt discutió la situación de los refugiados y judíos durante la Segunda Guerra Mundial, sus palabras aplican igual de bien para los migrantes indocumentados hoy en día:

la primera pérdida que tuvieron las personas sin derechos sufrieron fue la pérdida de sus hogares, y esto

significa la pérdida completa del contexto social en el que nacieron y el cual se establecieron como un lugar distinto en el mundo... lo que es inaudito no es la pérdida de su hogar sino la imposibilidad de encontrar uno nuevo. De repente, no había un lugar en el mundo donde los migrantes pudiesen ir sin restricciones severas, no había país donde los asimilasen, no había territorio donde pudieran encontrar una nueva comunidad para ellos (Arendt, 1973).

Además, anunciando la "nuda vida" de Agamben, ella muestra cómo la concepción de los derechos humanos se quebró frente a la migración masiva:

La concepción de los derechos humanos se quebró en el momento en que aquellos que profesaban creer en ella, por primera vez se confrontaron con las personas que de hecho habían perdido todas sus cualidades y relaciones específicas - excepto que aún eran humanos. El mundo no encontró nada sagrado en la desnudez abstracta de ser humano (Arendt, 1973).

Si los migrantes indocumentados viven la "vida nuda" de los que no tienen derechos, lo experimentan en el miedo concreto y cotidiano a la detención y deportación. El número de deportaciones ha ido creciendo en EE.uU., durante la última década ha alcanzado casi medio millón en el 2013 (Gonzalez-Barrera \& Krogstad, 2014). No hubo reforma integral para la inmigración durante el gobierno del Presidente Obama y sus decretos en favor de menores indocumentados peligran con la administración Trump. Si tener trabajos precarios con un pago muy bajo y en condiciones laborales de inseguridad no es suficiente, en su estado de "vida nuda", los inmigrantes indocumentados detenidos no tienen ningún derecho, a diferencia de los criminales, ellos no tienen el derecho a un defensor público, un intérprete o una audiencia imparcial entre otras limitaciones (Johnson, 2004; Massey \& Bartley, 2005; Schuck, 1998). Los derechos humanos fallan cuando se trata de proteger los derechos de los migrantes indocumentados (Noll, 2010).

El miedo generalizado a la deportación lo expresa Blas con una foto tomada desde la ventana de un segundo piso. 


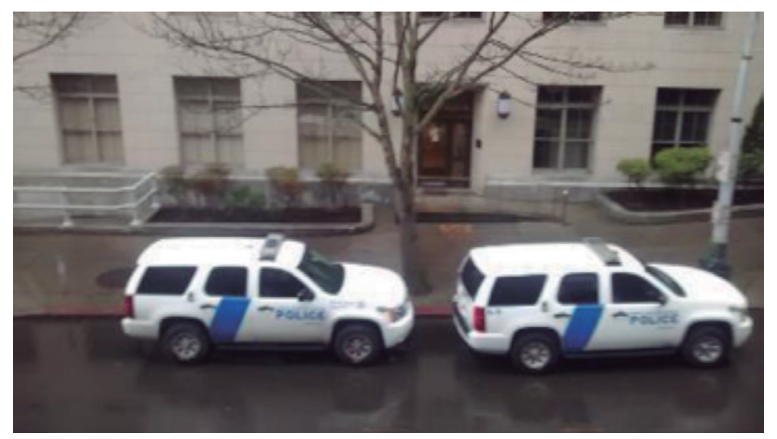

Carros de policía. Foto: Blas

-Blas: Tomé esta foto en el centro porque a veces de solo verlos, a los carros de la migra, te da miedo. A veces te da miedo solo verlos. Uno desea no tener que verlos porque te van a hacer preguntas, solo por precaución. Así que por eso es que tomé esa foto, por el miedo que tengo de verlos. Yo estaba feliz de poder tomar esa foto.

-Vero: ¿Así no estés haciendo nada malo, te parecen intimidantes?

-Blas: Sí, claro, porque están mirando y no sé si te van a querer hacer preguntas y es como si estuvieran buscándote. Me da miedo. Uno tiene que portarse bien y trabajar honestamente para no meterse en problemas. Yo no quisiera estar en uno de esos carros en este momento.

Desde la seguridad de una ventana de un segundo piso Blas pudo tomar una foto del carro de policía al que no quiere subirse, aunque no haya cometido ningún crimen. Todos los sueños y las aspiraciones de ir a EE.uu. y conseguir un trabajo, ahorrar dinero para darle educación a los hijos y regresar después de unos pocos años con dinero ahorrado, esos sueños se destruyen al ver un carro de policía que le recuerda a Blas el miedo constante a la deportación.

El "Sueño Americano" resultó ser una mentira, dice Juan, después de explicar que él realmente no estaba durmiendo, que le pidió a alguien que le tomara una foto de él pretendiendo dormir, pretendiendo soñar el "Sueño Americano".

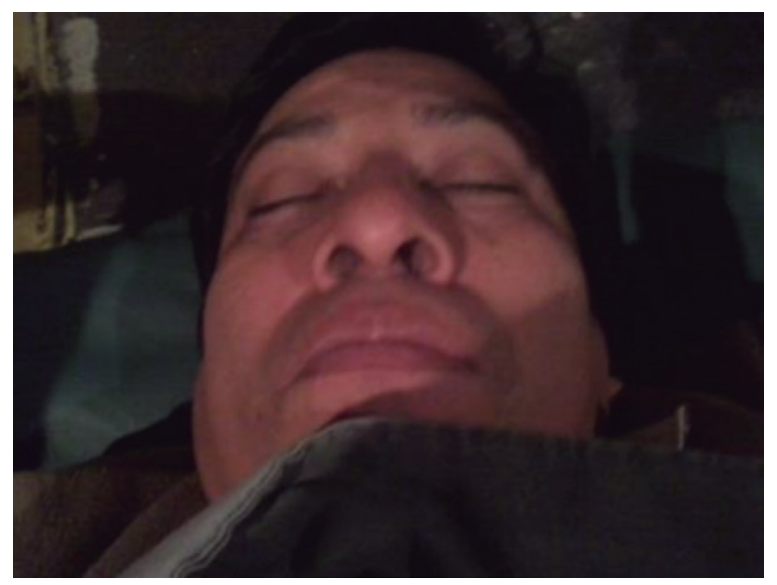

El sueño americano. Foto: Juan 


\section{DISERTACIONES}

AVANCES

Juan: Este es mi sueño americano. Para mí y para todos los hispanos que estamos aquí, el sueño es ir a los Estados. Piensas: "Oh, voy a ganar dólares y volver a Guatemala y comprar un buen carro, una buena casa, tener vacas, etc.". Así que en esta foto estoy durmiendo y soñando mi sueño americano de venir a los Estados y ganar dólares, canastas de dinero y volver a mi tierra siendo rico. Pero entonces llegas aquí y te das cuenta que no es así. ¿Dónde están los dólares?, ¿dónde están las riquezas?, ¿dónde se recoge todo el dinero? Todo son mentiras. El sueño americano del que todos hablan no es así.

A pesar del miedo constante y todas las limitaciones que ellos tienen para encontrar un trabajo, tener una vida con sentido, productiva y legal, los migrantes indocumentados expresan un fuerte sentido de orgullo frente a lo que han logrado desde que llegaron a EE.uu. Como mostrando el mundo en el que están más que la "vida nuda" a la que el estado de indocumentados podría reducirlos, ellos están acá y iestán vivos! Sin embargo, la vida como un migrante indocumentado en Seattle no es fácil. Para la mayoría de los participantes en nuestra investigación el trabajo es precario, difícil de conseguir y con un pago muy bajo. Añorando el hogar mientras construyen un hogar, los migrantes indocumentados están entre la vida "aquí" y la vida "allá", y frecuentemente encuentran un camino para darle sentido a su pertenencia a ambos lugares al mismo tiempo. Su existencia como Homo Sacer de "vida nuda" y el sentido de transitoriedad e impermanencia están resaltados por el miedo constante a la deportación, tratan de conciliar el orgullo que tienen de lo que han logrado y la desilusión del "Sueño Americano" que no fue. Y aun así perseveran.

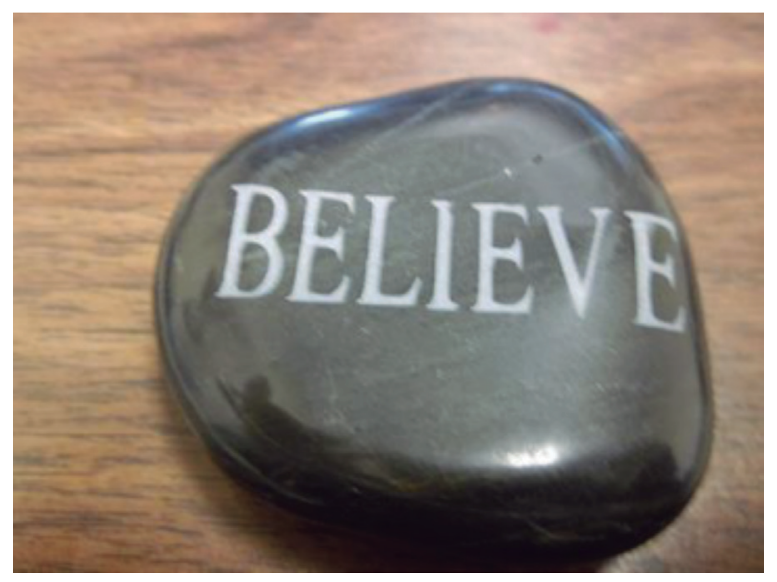

Believe. Foto: Gilda

Gilda: Esta última foto es una piedra con la palabra "believe" (creer). Cada día la cargo conmigo en mi bolso. Cuando salgo de casa la tengo en mi abrigo. Tengo que creer en mí misma. Tengo que creer en la vida. Tengo que creer en los otros. ¡Tengo que creer en tantas cosas! Cosas por las que quiero luchar, porque si se lucha con fe, puedes conseguir muchas cosas. La fe es algo que mantengo porque soy humana. La debilidad me haría desaparecer. Con fe y esperanza, uno puede seguir saliendo adelante. 


\section{DISERTACIONES}

AVANCES

Estudios de audiencias y recepción: audiencias minoritarias y nuevas mediaciones

ISSN: 1856-9536

Doi: http://dx.doi.org/10.12804/revistas.urosario.edu.co/disertaciones/v11i1

Volumen 11, Número 1/ Enero-junio 2018

Versión PDF para imprimir desde

http://revistas.urosario.edu.co/index.php/disertaciones

\section{Conclusión}

Las historias de migración descubiertas a través de las fotohistorias son abundantes y variadas; ofrecen un caleidoscopio de experiencias rico en texturas que nos ayuda a entender la noción de hogar desde la perspectiva de los migrantes. Los migrantes transnacionales, en el punto decisivo de la transición en la frontera de México y Ee.uu., presentan una imagen diferente. Su "vida nuda" se manifiesta en la incertidumbre de su impermanencia y en la bolsa de plástico o morral que cargan con sus pertenencias mínimas; pero su humanidad se reaviva con el apoyo y la solidaridad que reciben unos de otros y de las organizaciones humanitarias que los ayudan, mientras se embarcan en el viaje para seguir sus sueños de un futuro mejor. En la mitad del vórtice de la transición entre "aquí" y "allá", los transmigrantes en la frontera viven suspendidos en el presente, un presente en el que el pasado y el futuro no son más que un sueño.

Lo migrantes transnacionales (con frecuencia indocumentados) ya establecidos en Seattle, Washington, presentan otra imagen que completa el tríptico de las experiencias de migración revelado por las fotohistorias. Situados en una existencia precaria e impermanente, con el miedo constante a la deportación, viven diferentes grados de apego a un hogar: el lugar de nacimiento donde el cordón umbilical está enterrado. Esta experiencia se vive en contraposición al orgullo de haber construido un hogar "en este lugar", donde viven en el presente. Algunos a veces viven en la calle, otros tienen hogares más permanentes en apartamentos arrendados que frecuentemente comparten con otros migrantes. Pero tener o no un hogar permanente no necesariamente significa que están más o menos apartados del hogar de sus raíces.

La migración involucra un movimiento en el que ni el lugar de partida ni el de llegada son inmutables o certeros. El migrante en las fotohistorias hace un llamado a habitar en el lenguaje, en las historias, en las identidades que están constantemente sujetas a cambio. Siempre en tránsito, el proceso de volver a casa -completando la historia, domesticando el desvío- se vuelve una imposibilidad (Chambers, 2008). Diferentes estudiosos han investigado cómo los migrantes mantienen o niegan su cultura cuando llegan a un nuevo país: "En el pasado los inmigrantes eran forzados a abandonar, olvidar o negar las ataduras a sus hogares y las memorias de conexiones trasnacionales de la generaciones subsecuentes eran borradas" (Schiller, Basch, \& Blanc, 1995). Berry (1984), seguido por Klandermans et al. (2008) sugirieron cuatro posibilidades de adaptación, "integración (identificación con ambas culturas), asimilación (única identificación con la cultura del país de inmigración), separación (única identificación con la cultura del país de origen) y marginalización (identificación con ninguna cultura)" (Klandermans et al., 2008).

Los participantes de las fotohistorias en los lugares de estudio entran en alguna de estas cuatro categorías de adaptación, pero ninguna es única y particular a algún lugar de estudio, son un híbrido de culturas. Gonzalez et al. $(2003 ; 2009)$ sugieren la noción de identidad dual en la que "la identificación con una entidad subordinada (ej. identidad étnica) no necesariamente excluye la identificación con una entidad superordinada (ej. identidad nacional)". De hecho afirman que "la identidad dual es una configuración deseada, pues implica suficiente identificación con el propio subgrupo para tener seguridad básica y suficiente identificación con el grupo general para impedir división" (González \& Brown, 2003). La idea de la identidad dual podría usarse para entender el sentido de pertenencia simultáneo a "aquí" y "allá" que experimentan los migrantes tanto en la comunidad fronteriza de Nogales como en la comunidad de transmigrantes hispanos indocumentados en Seattle. 


\section{DISERTACIONES}

AVANCES

Estudios de audiencias y recepción: audiencias minoritarias y nuevas mediaciones

ISSN: 1856-9536

Doi: http://dx.doi.org/10.12804/revistas.urosario.edu.co/disertaciones/v11i1

Volumen 11, Número 1 / Enero-junio 2018

Versión PDF para imprimir desde

http://revistas.urosario.edu.co/index.php/disertaciones

Phinney et al. (2001) argumentan que cuando un inmigrante llega a un nuevo país sus actitudes hacia mantener o no la cultura de su país de origen son determinadas por el país que lo recibe:

Inmigrantes individuales llegan a un nuevo país con diferentes actitudes en cuanto a conservar su cultura de origen y hacer parte de la nueva sociedad. En la nueva sociedad estas actitudes interactúan con los niveles percibidos de aceptación de los inmigrantes y con las políticas oficiales hacia la inmigración ( $p$. 494).

Los migrantes indocumentados que llegan a EE.Uu. encuentran un país que promete resolver sus aspiraciones de vivir "el sueño americano" pero que les niega todos los derechos y los excluye de su ser político, un Estado que los reduce a la "vida nuda" del Homo Sacer, un ser fungible al que pueden matar pero no sacrificar (Agamben, 1998). Afrontando este olvido de sí, los migrantes indocumentados no tienen otra opción que mantener su cultura original, y solo renunciar a ella bajo coerción o después de un largo periodo de tiempo. En concordancia con Hernandez et al. (2007; 2001), es más posible que los migrantes indocumentados entiendan el apego a un lugar y la identidad de un lugar como dos ideas separadas:

El apego a un lugar [es el] vínculo afectivo que las personas establecen con un entorno específico, donde tienden a quedarse y donde se sienten cómodos y seguros, [mientras que] la identidad con un lugar sería un componente de la identidad personal, que se desarrolla de acuerdo con los elementos que tipifican un área específica y la naturaleza de las interacciones que allí ocurren (Hernández, Carmen Hidalgo, Salazar-Laplace, \& Hess, 2007, p. 310, citando a Hidalgo \& Hernández, 2001).

En nuestra investigación, todos los participantes expresaron un sentido de identidad con y apego a un lugar, pero la fórmula particular para la combinación de ambas varía de lugar a lugar, y especialmente, de persona a persona.

Los migrantes transnacionales en la frontera México-EE.uu. y en Seattle añoran encontrar un lugar al que puedan llamar hogar, quizás sabiendo muy bien que el hogar es lo que se lleva dentro, lo que da identidad, lo que le da sentido y significado al territorio del alma. Identidad y territorio son los últimos vestigios de una humanidad en la "vida nuda" del Homo Sacer.

Agradecimientos: Con contribuciones de Staci Fox, Sara Vannini, Veronica Guajardo y Bryce Newell, de la Facultad de Información de la Universidad de Washington. Ayuda en traducción de Irene Bermúdez Rivera. Agradecemos la colaboración de las organizaciones y participantes en Mexico y EE.uu., quienes con sus fotos y sus historias hicieron posible este estudio.

\section{Referencias}

1. Agamben, G. (1998). Homo Sacer: Sovereign Power and Bare Life. Stanford University Press. Recuperado de http://www.sup.org/books/title/?id=2003

2. Arendt, H. (1973). The Origins of Totalitarianism. New York: Harcourt, Brace, Jovanovich.

3. Baron, L. F., Neils, M., \& Gomez, R. (2014). Crossing new borders: computers, mobile phones, transportation, and English language among Hispanic day laborers in Seattle, Washington. Journal of the Association for Information Science and Technology, 65(1), 98-108. Recuperado de https://doi.org/10.1002/asi.22949

4. Berry, J. W. (1984). Cultural relations in plural societies: Alternatives to segregation and their sociopsychological implications. Groups in Contact: The Psychology of Desegregation, 11-27. 


\section{DISERTACIONES}

AVANCES

Estudios de audiencias y recepción: audiencias minoritarias y nuevas mediaciones

ISSN: 1856-9536

Doi: http://dx.doi.org/10.12804/revistas.urosario.edu.co/disertaciones/v11i1

Volumen 11, Número 1 / Enero-junio 2018

Versión PDF para imprimir desde

http://revistas.urosario.edu.co/index.php/disertaciones

5. Bignante, E. (2010). The use of photo-elicitation in field research. EchoGéo, (11). Recuperado de http:// echogeo.revues.org/11622

6. Caidi, N., Allard, D., \& Quirke, L. (2010). Information practices of immigrants. Annual Review of Information Science and Technology, 44(1), 491-531.

7. Chambers, I. (2008). Migrancy, Culture, Identity. Londres: Routledge.

8. Converti, L. (2015). Young voices from the border: Fear and unaccompanied migrant children. Recuperado de http://www.coha.org/young-voices-from-the-border-fear-and-unaccompanied-migrant-children/

9. Fisher, K., Marcoux, E., Miller, L., Sanchez, A., \& Ramirez Cunningham, E. (2004). Information Behavior of Migrant Hispanic Farm Workers and their Families in the Pacific Northwest. Information Research, 10. Recuperado de http://informationr.net/ir/10-1/paper199.html

10. Frohmann, L. (2005). The Framing Safety Project Photographs and Narratives by Battered Women. Violence Against Women, 11(11), 1396-1419. Recueprado de https://doi.org/10.1177/1077801205280271

11. Gomez, R., \& Vannini, S. (2015). Fotohistorias: Participatory Photography and the Experience of Migration. Charleston: CreateSpace.

12. González, R., \& Brown, R. (2003). Generalization of positive attitude as a function of subgroup and superordinate group identifications in intergroup contact. European Journal of Social Psychology, 33(2), 195214. Recuperado de https://doi.org/10.1002/ejsp.140

13. Gonzalez, V., Castro, L. A., \& Rodriguez, M. (2009). Technology and connections Mexican immigrants in the U.S. IEEE Technology and Society Magazine, 28, $42-48$.

14. Gonzalez-Barrera, A., \& Krogstad, J. M. (2014, October 2). u.s. deportations of immigrants reach record high in 2013. Recuperado de http://pewrsr.ch/Zx2c6E

15. Hernández, B., Carmen Hidalgo, M., Salazar-Laplace, M. E., \& Hess, S. (2007). Place attachment and place identity in natives and non-natives. Journal of Environmental Psychology, 27(4), 310-319. Recuperado de https://doi.org/10.1016/j.jenvp.2007.06.003

16. Hidalgo, M. C., \& Hernández, B. (2001). Place attachment: Conceptual and empirical questions. Journal of Environmental Psychology, 21(3), 273-281. Recuperado de https://doi.org/10.1006/jevp.2001.0221

17. Holgate, J., Keles, J., \& Kumarappan, L. (2012). Visualizing 'community': An experiment in participatory photography among Kurdish diasporic workers in London. The Sociological Review, 60(2), 312-332. Recuperado de https://doi.org/10.1111/j.1467-954X.2012.02075.x

18. ITEP. (2013). Undocumented Immigrants' State and Local Tax Contributions. Washington DC, USA: Institute of Taxation and Economic Policy. Recuperado de http://www.itep.org/pdf/undocumentedtaxes.pdf

19. Jensen, B. (2002). Service to day laborers: A job libraries have left undone. Reference \& User Services Quarterly, 41, 228-33.

20. Johnson, K. (2004). Driver's Licenses and Undocumented Immigrants: The future of civil rights law? Nevada Law Journal, 5(1). Recuperado de http://scholars.law.unlv.edu/nlj/vol5/iss1/11

21. Klandermans, B., Van der Toorn, J., \& Van Stekelenburg, J. (2008). Embeddedness and identity: How immigrants turn grievances into action. American Sociological Review, 73(6), 992-1012. 


\section{DISERTACIONES}

AVANCES

Estudios de audiencias y recepción: audiencias minoritarias y nuevas mediaciones

ISSN: 1856-9536

Doi: http://dx.doi.org/10.12804/revistas.urosario.edu.co/disertaciones/v11i1

Volumen 11, Número 1/ Enero-junio 2018

Versión PDF para imprimir desde

http://revistas.urosario.edu.co/index.php/disertaciones

22. Kwok, J. Y., \& Ku, H.-B. (2008). Making habitable space together with female Chinese immigrants to Hong Kong An interdisciplinary participatory action research project. Action Research, 6(3), 261-283. Recuperado de https://doi.org/10.1177/1476750308094131

23. Lee, B. A., Tyler, K. A., \& Wright, J. D. (2010). The new homelessness revisited. Annual Review of Sociology, 36(1), 501-521. Recuperado de https://doi.org/10.1146/annurev-soc-070308-115940

24. Massey, D. S., \& Bartley, K. (2005). The Changing Legal Status Distribution of Immigrants: A Caution. International Migration Review, 39(2), 469-484. Recuperado de https://doi.org/10.1111/j.1747-7379.2005. tb00274.x

25. Nail, T. (2015). The figure of the migrant. Stanford University Press.

26. Newell, B. C., \& Gomez, R. (2014). Informal networks, phones and facebook: Information seeking and technology use by undocumented migrants at the u.s.-Mexico border. Ponencia presentada en iConference 2015, Rochester, Nueva York. Recuperado de http://papers.ssrn.com/abstract=2539396

27. Newell, B. C., Gomez, R., \& Guajardo, V. E. (2016). Information seeking, technology use, and vulnerability among migrants at the United States-Mexico border. The Information Society, 32(3), 176-191. Recuperado de https://doi.org/10.1080/01972243.2016.1153013

28. Noll, G. (2010). Why human rights fail to protect undocumented migrants. European Journal of Migration and Law, 12. Recuperado de https://works.bepress.com/gregor_noll/9/

29. Passel, J. S., \& Cohn, D. (2011). Unauthorized Immigrant Population: National and State Trends, 2010 (Pew Research Center). Pew Hispanic Center. Retrieved from http://pewhispanic.org/files/reports/133. pdf\#page $=25$

30. Perryman Group. (2008). An analysis of the economic impact of undocumented workers on business activity in the us with estimated effects by state and by industry. Recuperado de http://www.ilw.com/articles/2008,1008-perryman.pdf

31. Phinney, J. S., Horenczyk, G., Liebkind, K., \& Vedder, P. (2001). Ethnic identity, immigration, and well-being: An interactional perspective. Journal of Social Issues, 57(3), 493-510. Recuperado de https://doi. org/10.1111/0022-4537.00225

32. Rhodes, S. D., Hergenrather, K. C., Griffith, D. M., Yee, L. J., Zometa, C. S., Montaño, J., \& Vissman, A. T. (2009). Sexual and alcohol risk behaviours of immigrant Latino men in the South-eastern uSA. Culture, Health \& Sexuality, 11(1), 17-34. Recuperado de https://doi.org/10.1080/13691050802488405

33. Savolainen, R. (2008). Everyday information practices: a social phenomenological perspective. Scarecrow Press.

34. Schiller, N. G., Basch, L., \& Blanc, C. S. (1995). From immigrant to transmigrant: Theorizing transnational migration. Anthropological Quarterly, 48-63.

35. Schuck, P. H. (1998). Citizens, strangers, and in-betweens: essays on immigration and citizenship. Westview Press.

36. Sutherland, C., \& Cheng, Y. (2009). Participatory-Action research with (im)migrant women in two small canadian cities: Using photovoice in Kingston and Peterborough, Ontario. Journal of Immigrant \& Refugee Studies, 7(3), 290-307. Recuperado de https://doi.org/10.1080/15562940903150089

37. Vannini, S., Gomez, R., \& Guajardo, V. (2016). Security and activism: Using participatory photography to elicit perceptions of Information and authority among Hispanic migrants in the u.s. Ponencia presentada en iConference 2016, Philadelphia, PA. 